\title{
The Effect of CO Adsorption at Room Temperature on the Structure of Supported Pt Particles
}

\author{
Barbara L. Mojet, ${ }^{* \dagger}$ Jeffrey T. Miller, ${ }^{\dagger}$ and Diederik C. Koningsberger ${ }^{\dagger}$ \\ Debye Institute, Department of Inorganic Chemistry, Utrecht University, P.O. Box 80083, 3508 TB Utrecht, \\ The Netherlands, and Amoco Research Center, E-1F, 150 West Warrenville Road, Naperville, Illinois 60563
}

Received: August 5, 1998; In Final Form: December 31, 1998

\begin{abstract}
To improve the understanding of the applicability of CO-FTIR spectroscopy for probing the electronic properties of catalysts, the effect of $\mathrm{CO}$ adsorption on the geometry of small metal particles in Pt/LTL and $\mathrm{Pt} / \mathrm{SiO}_{2}$ catalysts with varying support acidities was determined by comparison of X-ray absorption spectra before and after $\mathrm{CO}$ adsorption. At room temperature, the platinum particles (first shell coordination number $N>5)$ supported on $\mathrm{SiO}_{2}$ were stable under $\mathrm{CO}$ atmosphere. By contrast, the smaller platinum particles $(N$ $<5$ ) in zeolite LTL reconstructed with the formation of very small platinum-CO aggregates upon admission of $\mathrm{CO}$ at room temperature. For both $\mathrm{Pt} / \mathrm{SiO}_{2}$ and $\mathrm{Pt} / \mathrm{LTL}$ the linear-to-bridge ratio (L/B) of the $\mathrm{CO}$ infrared bands is a function of the support acidity/alkalinity. In the case of $\mathrm{Pt} / \mathrm{SiO}_{2}$, the $\mathrm{L} / \mathrm{B}$ ratio directly reflects the electronic properties of the catalytically active metal, since the metal particles do not reconstruct. The results show that the structure of the platinum particles in LTL zeolite, which participate in catalytic reactions is not the same as the $\mathrm{Pt}-\mathrm{CO}$ aggregate analyzed by FTIR. Nevertheless, both the catalytic activity and L/B ratio are a function of support acidity.
\end{abstract}

\section{Introduction}

Infrared spectroscopy of adsorbed $\mathrm{CO}$ is an established technique to characterize supported metal particles. ${ }^{1-7}$ Several factors affect the FTIR spectra, like particle size, surface coverage, and ion-dipole interactions. For example, the $\mathrm{CO}$ absorption band was suggested to consist of separate contributions of $\mathrm{CO}$ adsorbed on sites with different metal-metal coordination numbers. ${ }^{1}$ Since the surface of a metal particle consists of atoms with different coordination numbers due to their location at edges, corners, or faces, ${ }^{2}$ the metal particle size determines the final shape of the $\mathrm{CO}$ absorption band. Also, ion-dipole interactions between adsorbed $\mathrm{CO}$ and cations in zeolite lattices were shown to introduce a fine structure in the spectra. ${ }^{3}$ Third, the frequency of the absorption band increases with higher surface coverage due to dipole-dipole interactions between adjacent $\mathrm{CO}$ molecules. ${ }^{4}$ The integrated intensity ratio of linear/bridge (L/B) bound CO was found to depend on the electron density of a metal surface by both experimental ${ }^{5,6}$ as well as theoretical studies. ${ }^{7}$ The higher the electron density of the metal, the lower the L/B ratio. This phenomenon was used to determine the influence of support acidity/alkalinity on the electron density of supported metal particles. ${ }^{5,6}$

Despite the general application of FTIR of adsorbed CO for characterization of supported metal catalysts, interpretation of the infrared data is still a matter of debate. Recently, Stakheev and co-workers presented an infrared study on Pt/K-LTL as a function of $\mathrm{CO}$ partial pressure. ${ }^{8}$ In that study, they suggested that $\mathrm{CO}$ induces the formation of new, neutral platinumcarbonyl clusters inside the zeolite. While anionic platinum

* Corresponding author. Present address: Schuit Institute for Catalysis, Eindhoven University of Technology, P.O. Box 513, 5600 MB Eindhoven, The Netherlands.

Utrecht University.

Amoco Research Center. clusters can be synthesized from precursor complexes as [Pt$\left.\left(\mathrm{NH}_{3}\right)_{4}\right]^{2+}$ and $\mathrm{CO},{ }^{9-12}$ these complexes have not been prepared from reduced platinum metal particles. EXAFS and FTIR studies have shown the reconstruction of reduced rhodium particles supported on $\mathrm{Al}_{2} \mathrm{O}_{3}$ or $\mathrm{TiO}_{2}$ after admission of $\mathrm{CO},{ }^{13,14}$ resulting in monorhodium-carbonyl clusters. In addition, a metal particle size effect for rhodium was shown. Rhodium particles with an average first shell coordination number $N \sim 7$ did not reconstruct under $\mathrm{CO}$ atmosphere while very small metal particles $(N \sim 4)$ formed Rh geminal carbonyl complexes. ${ }^{15}$

Shifts in the frequency and changes in the linear-to-bridged ratio are often used to probe indirectly the metal electron density near the Fermi-level in order to correlate electronic structure with observed catalytic activity. For example, for platinum and palladium catalysts the turnover frequency for neopentane hydrogenolysis decreases with increasing support alkalinity. 5,6 In addition, the integrated intensity ratio linear to bridged bound $\mathrm{CO}$ decreased in the same order. ${ }^{5,6,16}$ Furthermore, for $\mathrm{Pt} / \mathrm{SiO}_{2}$ there was a linear correlation of the linear/bridged ratio with catalytic activity. ${ }^{6}$ For Pt/LTL catalysts the correlation was nonlinear.

To better understand the applicability of linear-to-bridged ratio of adsorbed $\mathrm{CO}$ for probing the electronic properties of catalysts, the effect of $\mathrm{CO}$ adsorption on the geometry of small metal particles in $\mathrm{Pt} / \mathrm{LTL}$ and $\mathrm{Pt} / \mathrm{SiO}_{2}$ with varying support acidities has been determined by XAFS spectroscopy. X-ray absorption data show that the larger platinum particles supported on $\mathrm{SiO}_{2}$ are stable, while the smaller platinum particles on zeolite LTL reconstruct upon exposure to $\mathrm{CO}$ at room temperature. It is proposed that platinum-CO aggregates are formed in LTL zeolite. The different behavior toward $\mathrm{CO}$ for $\mathrm{Pt} / \mathrm{SiO}_{2}$ and $\mathrm{Pt} /$ LTL is most likely due to the larger metal particles on $\mathrm{SiO}_{2}$. The applicability of CO-FTIR spectroscopy for probing electronic properties of catalysts is also discussed. 
TABLE 1: Elemental Analysis and Platinum Dispersion

\begin{tabular}{lcccc}
\multicolumn{1}{c}{ catalyst } & wt. \% K & wt. \% Al & wt. \% Pt & $\mathrm{H} / \mathrm{Pt}$ \\
\hline $\mathrm{Pt} / \mathrm{LTL}(0.63)$ & 8.3 & 9.5 & 1.0 & 0.53 \\
$\mathrm{Pt} / \mathrm{LTL}(0.96)$ & 11.8 & 8.5 & 1.0 & 0.89 \\
$\mathrm{Pt} / \mathrm{LTL}(1.25)$ & 15.9 & 8.8 & 1.0 & 0.88 \\
$\mathrm{Pt} / \mathrm{SiO}_{2}-\mathrm{Al}(0.10)$ & & 0.10 & 1.54 & 0.60 \\
$\mathrm{Pt} / \mathrm{SiO}_{2}$ & & & 1.40 & 0.58 \\
$\mathrm{Pt} / \mathrm{SiO}_{2}-\mathrm{K}(1.14)$ & 1.14 & & 1.48 & 1.35
\end{tabular}

\section{Experimental Section}

Catalyst Preparation. The acidity of the LTL zeolite support was varied by either impregnating a commercial K-LTL zeolite with $\mathrm{KNO}_{3}$ or exchanging with $\mathrm{NH}_{4} \mathrm{NO}_{3}$ to give $\mathrm{K} / \mathrm{Al}$ ratios ranging from 0.63 to 1.25 . Each LTL zeolite was calcined at $225^{\circ} \mathrm{C}$ and analyzed for potassium and aluminum. Platinum was added by incipient wetness impregnation with $\left[\mathrm{Pt}\left(\mathrm{NH}_{3}\right)_{4}\right]$ $\left(\mathrm{NO}_{3}\right)_{2}$ followed by drying at $120{ }^{\circ} \mathrm{C}$. The catalysts are designated Pt/LTL $(x)$ with $(x)$ representing the $\mathrm{K} / \mathrm{Al}$ molar ratio.

The silica supports were prepared by ion exchange of $\mathrm{SiO}_{2}$ ( $15 \mathrm{~g}$ in $500 \mathrm{~mL}$ of $\mathrm{H}_{2} \mathrm{O}$ at $60{ }^{\circ} \mathrm{C}$ ) with increasing amounts of $\mathrm{KOH}$ followed by calcination at $400{ }^{\circ} \mathrm{C}$. Also, an acidic silica was prepared by ion exchange of $\mathrm{SiO}_{2}$ with excess of $\mathrm{Al}\left(\mathrm{NO}_{3}\right)_{3}$ followed by washing, drying, and calcination at $400{ }^{\circ} \mathrm{C}$. Platinum was added by incipient wetness impregnation with [Pt$\left.\left(\mathrm{NH}_{3}\right)_{4}\right]\left(\mathrm{NO}_{3}\right)_{2}$ followed by calcination at $225^{\circ} \mathrm{C}$. The catalysts are designated $\mathrm{Pt} / \mathrm{SiO}_{2}-X$ with $X$ representing the wt $\% \mathrm{Al}$ or $\mathrm{K}$.

Metal dispersion was determined by $\mathrm{H}_{2}$ chemisorption after reduction at $300{ }^{\circ} \mathrm{C}$ according to the double isotherm method. The dispersion $(\mathrm{H} / \mathrm{Pt})$ and the elemental analysis of all catalysts are reported in Table 1.

Fourier Transform Infrared Spectroscopy. The transmission infrared spectra were recorded on a Perkin-Elmer 1720-X Fourier transform spectrometer at a spectral resolution of $4 \mathrm{~cm}^{-1}$. The catalysts were pressed in thin self-supporting wafers and placed in an in-situ transmission infrared cell. The catalyst was reduced in $\mathrm{H}_{2}$ at $300{ }^{\circ} \mathrm{C}$ and cooled to room temperature. Subsequently, the sample was purged with $\mathrm{He}$ for $10 \mathrm{~min}$ followed by flowing $20 \% \mathrm{CO}$ in $\mathrm{He}$ gas for $10 \mathrm{~min}$, after which the $\mathrm{CO}$ absorbance spectrum was collected. The samples are denoted by Pt/LTL-[CO] or $\mathrm{Pt} / \mathrm{SiO}_{2}-[\mathrm{CO}]$. For the Pt/LTL catalysts a gas flow with a small amount of water was used to prevent ion-dipole interactions between $\mathrm{K}^{+}$and absorbed $\mathrm{CO} .{ }^{3}$ Spectra were corrected for the absorption of the support and gas-phase $\mathrm{CO}$.

X-ray Absorption Fine Structure (XAFS) Experiments. The samples were characterized by XAFS spectroscopy at the SRS Daresbury (U.K.) at Wiggler station 9.2, using a $\mathrm{Si}(220)$ double crystal monochromator. The measurements were done in transmission mode using ion chambers filled with Ar to have a $\mu x$ of $20 \%$ in the first and a $\mu x$ of $80 \%$ in the second ion chamber. The monochromator was detuned to $50 \%$ maximum intensity at $12250 \mathrm{eV}$ to avoid higher harmonics present in the $\mathrm{X}$-ray beam.

Each sample was pressed into a self-supporting wafer (calculated to have an absorbance of 2.5) and placed in an insitu cell. ${ }^{17}$ It was dried at $120{ }^{\circ} \mathrm{C}$ and subsequently reduced at $300{ }^{\circ} \mathrm{C}$ (heating rate $5^{\circ} \mathrm{C} / \mathrm{min}$ ) for $1 \mathrm{~h}$ in flowing hydrogen (purified and dried). Subsequently, the sample was cooled under flowing $\mathrm{H}_{2}$ and spectra were taken at liquid nitrogen temperature $\left(\mathrm{Pt} / \mathrm{LTL}\right.$ or $\left.\mathrm{Pt} / \mathrm{SiO}_{2}-X\right)$. The sample was allowed to warm to room temperature and exposed to a $\mathrm{CO} / \mathrm{He}(1 / 1)$ gas flow (purified and dried) for $15 \mathrm{~min}$ at room temperature. XAFS spectra were taken subsequently at liquid nitrogen temperature (Pt/LTL-[CO] or $\left.\mathrm{Pt} / \mathrm{SiO}_{2}-[\mathrm{CO}]\right)$.
XAFS Data Analysis. Data analysis was performed by multiple shell fitting in $R$-space. ${ }^{18}$ Different backscatterers were identified by applying the difference file technique ${ }^{19}$ using phase-corrected Fourier transforms. ${ }^{20}$ The difference file technique is based on the fact that a single scattering contribution in a model spectrum correctly describing the experimental data must be equal to the experimental spectrum minus all other model contributions:

$$
\chi_{i}=\chi_{\text {experiment }}-\sum_{j=1, j \neq i}^{n} \chi_{j} \quad \text { with } \quad \chi_{\text {model }}=\sum_{j=1}^{n} \chi_{j}
$$

Data for the phase shifts and backscattering amplitudes were obtained from reference compounds. Pt foil was used as a reference for $\mathrm{Pt}-\mathrm{Pt}$ contributions; $\mathrm{Na}_{2} \mathrm{Pt}(\mathrm{OH})_{6}$ was used for $\mathrm{Pt}-\mathrm{O}$ contributions. ${ }^{21}$ To analyze adsorbed $\mathrm{CO}, \mathrm{Pt}-\mathrm{C}$ and multiple scattering $\mathrm{Pt}-\mathrm{O} *$ references are necessary. XAFS data of crystalline $\operatorname{Ir}(\mathrm{CO})_{12}$ were used to extract $\mathrm{Ir}-\mathrm{C}$ and multiple scattering $\mathrm{Ir}-\mathrm{O}^{*}$ backscattering amplitudes and phase shifts. ${ }^{22}$ Since phase shift and backscattering amplitude are transferable between Pt and Ir, these data could be used to calculate a model spectrum for $\mathrm{Pt}-\mathrm{C}$ and $\mathrm{Pt}-\mathrm{O}^{*}$ contributions. ${ }^{22}$

The variances in imaginary and absolute parts were used to determine the fit quality, according to

$$
k^{n} \text { variance }=100 \frac{\int\left[k^{n}\left(\mathrm{FT}_{\text {model }}(R)-\mathrm{FT}_{\text {experiment }}(R)\right)\right]^{2}}{\int\left[k^{n} \mathrm{FT}_{\text {experiment }}(R)\right]^{2}}
$$

Models with variances in absolute and imaginary parts below $1 \%$ are considered to represent very good models for the experimental data. The errors in the fit parameters are estimated to be $5 \%$ in coordination number $(N), 1 \%$ in distance $(R), 5 \%$ in Debye-Waller factor $\left(\Delta \sigma^{2}\right)$, and $10 \%$ in inner potential correction $\left(\Delta E_{0}\right)$.

\section{Results}

EXAFS: Structure of $\mathrm{Pt} / \mathrm{LTL}$ and $\mathrm{Pt} / \mathrm{SiO}_{2}$ after Reduction. Parts $\mathrm{a}-\mathrm{f}$ of Figure 1 show the Fourier transforms of the XAFS data of $\mathrm{Pt} / \mathrm{LTL}$ and $\mathrm{Pt} / \mathrm{SiO}_{2}$ with varying support acidities. The dotted lines indicated the best fit obtained after $R$-space analysis; the parameters are given in Tables 2 and 3 . It can be seen that the metal particles in the Pt/LTL series are very small with average $\mathrm{Pt}-\mathrm{Pt}$ coordination numbers less than 4.5 . The long $\mathrm{Pt}-\mathrm{O}$ distance of approximately $2.68 \AA$ is in accordance with previous studies on Pt/LTL. ${ }^{23}$ No potassium could be detected near the platinum particles.

The $\mathrm{Pt} / \mathrm{SiO}_{2}$ series shows larger platinum particles with $\mathrm{Pt}-$ Pt coordination numbers between 5.3 and 7.6. Each catalyst also exhibited an oxygen contribution at around $2.2 \AA$. No potassium or aluminum could be detected near the platinum particles.

FTIR: Adsorption of $\mathrm{CO}$ on $\mathrm{Pt} / \mathrm{LTL}$ and $\mathbf{P t} / \mathrm{SiO}_{2}$. The transmission infrared spectra of $\mathrm{Pt} / \mathrm{LTL}$ and $\mathrm{Pt} / \mathrm{SiO}_{2}$ are shown in Figure 2a,b, respectively. Two regions of adsorbed $\mathrm{CO}$ can be assigned: at higher wavenumbers absorption due to linearly coordinated $\mathrm{CO}$ and at lower wavenumbers a band caused by $\mathrm{CO}$ in bridged coordination to the metal atoms. For Pt/LTL and $\mathrm{Pt} / \mathrm{SiO}_{2}$ the linear- as well as the bridged-coordinated $\mathrm{CO}$ absorption bands shifted to lower wavenumbers as the support alkalinity increased. The shifts are more pronounced for the Pt/ LTL series than for the $\mathrm{Pt} / \mathrm{SiO}_{2}$ series. The line shapes for $\mathrm{Pt} /$ $\mathrm{SiO}_{2}-\mathrm{Al}(0.10)$ and $\mathrm{Pt} / \mathrm{SiO}_{2}$ were sharper than that of $\mathrm{Pt} / \mathrm{SiO}_{2}-$ $\mathrm{K}(1.14)$ consistent with the different Pt particle sizes of the catalysts. ${ }^{1,2}$ Larger metal particles result in sharper absorption 

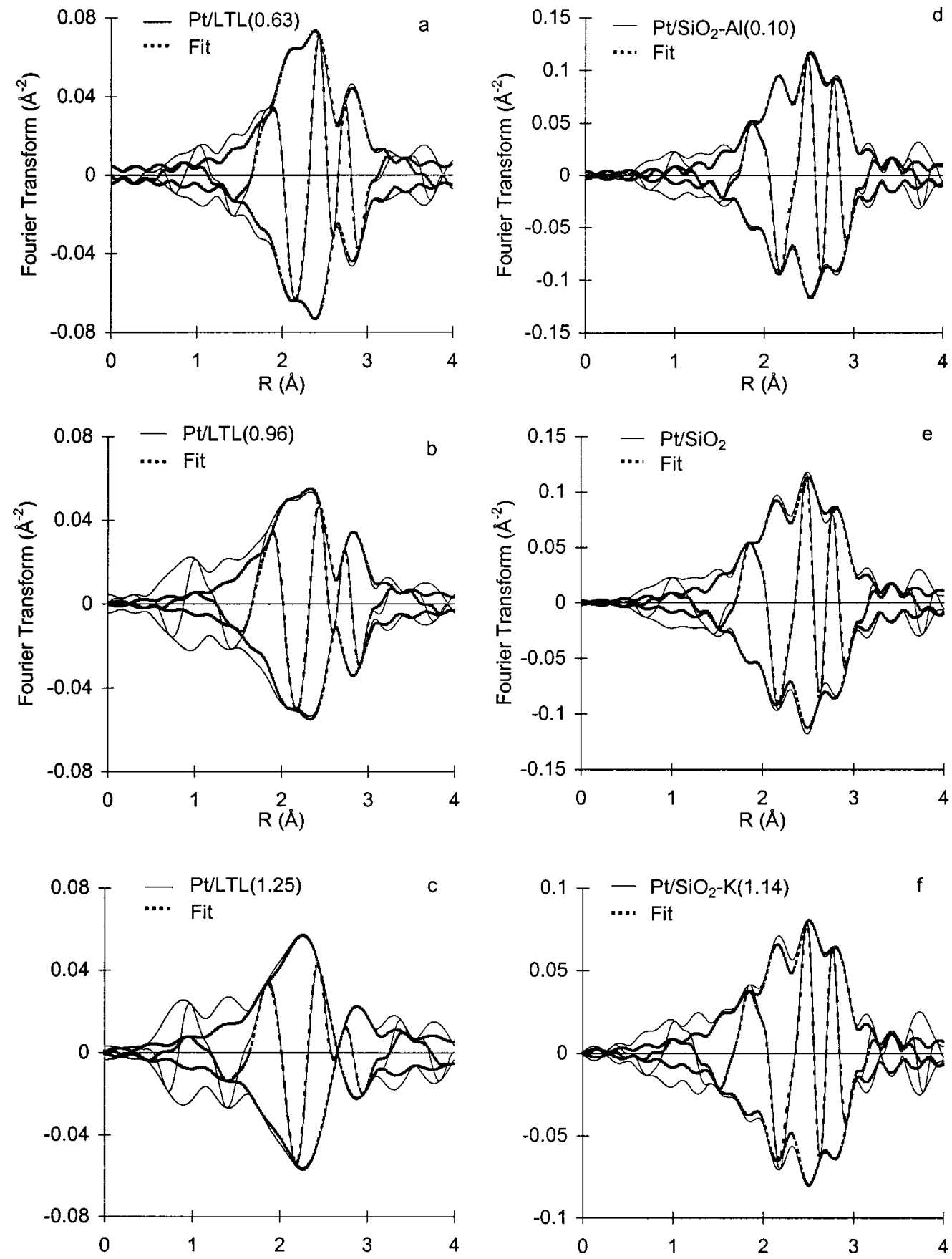

Figure 1. $k^{1}$-weigthed Fourier transforms of experimental data (solid line) and calculated model spectra (dotted line): (a) Pt/LTL(0.63), $\Delta k=$ 3.2-14.0 $\AA^{-1}$; (b) Pt/LTL(0.96), $\Delta k=3.2-14.0 \AA^{-1}$; (c) Pt/LTL(1.25), $\Delta k=3.2-11.0 \AA^{-1}$; (d) $\mathrm{Pt} / \mathrm{SiO}_{2}-\mathrm{Al}(0.10), \Delta k=3.2-14.8 \AA^{-1} ;(\mathrm{e})$ $\mathrm{Pt} / \mathrm{SiO}_{2}, \Delta k=3.2-14.8 \AA^{-1}$; (f) $\mathrm{Pt} / \mathrm{SiO}_{2}-\mathrm{K}(1.14), \Delta k=3.2-14.8 \AA^{-1}$.

TABLE 2: Fit Parameters $\left(\Delta k=3.2-14.0 \AA^{-1}, \Delta R=1.60-3.20(\AA)\right.$ and Variances for Model Spectra Pt/LTL

\begin{tabular}{|c|c|c|c|c|c|c|c|}
\hline \multirow[b]{2}{*}{ catalyst } & \multirow[b]{2}{*}{ scatterer } & \multirow[b]{2}{*}{$N( \pm 5 \%)$} & \multirow[b]{2}{*}{$R(\AA, \pm 1 \%)$} & \multirow[b]{2}{*}{$\Delta \sigma^{2}( \pm 5 \%)\left(10^{-3} \AA^{2}\right)$} & \multirow[b]{2}{*}{$\Delta E_{0}(\mathrm{eV})( \pm 10 \%)$} & \multicolumn{2}{|c|}{$k^{1}$-variance $(\%)$} \\
\hline & & & & & & im part & $\overline{\text { abs part }}$ \\
\hline \multirow{2}{*}{$\mathrm{Pt} / \operatorname{LTL}(0.63)$} & $\mathrm{Pt}$ & 3.7 & 2.74 & 4.6 & -2.2 & 0.7 & 0.4 \\
\hline & $\mathrm{O}$ & 2.1 & 2.69 & 4.8 & 7.3 & & \\
\hline \multirow[t]{2}{*}{ Pt/LTL(0.96) } & $\mathrm{Pt}$ & 4.5 & 2.74 & 3.5 & -1.5 & 0.6 & 0.4 \\
\hline & $\mathrm{O}$ & 1.6 & 2.68 & 0.9 & 4.5 & & \\
\hline \multirow[t]{2}{*}{$\operatorname{Pt} / \operatorname{LTL}(1.25)^{a}$} & $\mathrm{Pt}$ & 2.3 & 2.72 & 3.3 & 9.3 & 0.3 & 0.1 \\
\hline & $\mathrm{O}$ & 3.0 & 2.64 & 10.5 & 5.6 & & \\
\hline
\end{tabular}

${ }^{a} k=3.2-11.0 \AA^{-1}$, due to lower signal-to-noise ratio, as only one spectrum was available for this catalyst.

bands, with their maximum positioned at higher wavenumbers. The bigger platinum particles of $\mathrm{Pt} / \mathrm{SiO}_{2}-\mathrm{Al}(0.10)$ and $\mathrm{Pt} / \mathrm{SiO}_{2}$ are thus reflected in the $\mathrm{CO}$ absorption line shape. However, there is no relation between Pt particle size and the integrated intensity ratio linear/bridged (L/B) CO (Table 4). The small shoulder visible at $1940 \mathrm{~cm}^{-1}$ in the FTIR spectrum of Pt/LTL- 
TABLE 3: Fit Parameters $\left(\Delta k=3.2-14.8 \AA^{-1}, \Delta R=1.60-3.10 \AA\right)$ and Variances for Model Spectra $\mathrm{Pt} / \mathrm{SiO}_{2}$

\begin{tabular}{lccccccc}
\hline \multicolumn{1}{c}{ catalyst } & & & & & \multicolumn{2}{c}{$k^{1}$-variance $(\%)$} \\
$/ \mathrm{SiO}_{2}-\mathrm{Al}(0.10)$ & scatterer & $N( \pm 5 \%)$ & $R(\AA)( \pm 1 \%)$ & $\Delta \sigma^{2}\left(10^{-3} \AA^{2}\right)( \pm 5 \%)$ & $\Delta E_{0}(\mathrm{eV})( \pm 10 \%)$ & 0.4 & 0.5 \\
& $\mathrm{Pt}$ & 7.4 & 2.77 & 2.2 & -15.6 & 0.1 \\
$\mathrm{Pt} / \mathrm{SiO}_{2}$ & $\mathrm{O}$ & 0.5 & 2.23 & 3.0 & 2.1 & 0.7 \\
& $\mathrm{Pt}$ & 7.7 & 2.77 & 2.6 & -16.4 & 0.3 \\
$\mathrm{Pt} / \mathrm{SiO}_{2}-\mathrm{K}(1.14)$ & $\mathrm{O}$ & 0.5 & 2.21 & 1.2 & 1.2 & 0.6 \\
& $\mathrm{Pt}$ & 5.3 & 2.77 & 2.3 & -9.3 & 0.4
\end{tabular}
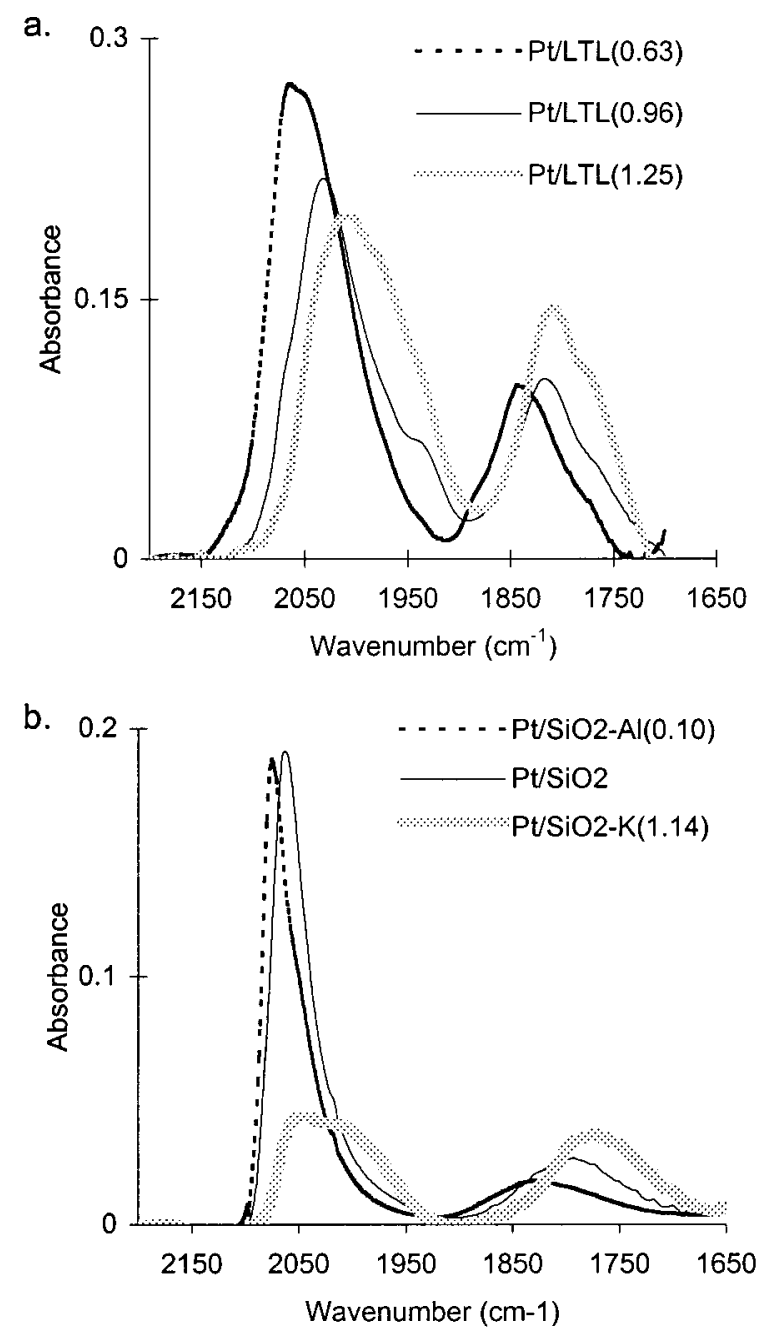

Figure 2. (a) Transmission FTIR spectra of $\mathrm{CO}$ adsorbed on Pt/LTL catalysts. (b) Transmission FTIR spectra of $\mathrm{CO}$ adsorbed on $\mathrm{Pt} / \mathrm{SiO}_{2}$ catalysts.

TABLE 4: Integrated Intensity Ratio Linear/Bridged Bound $\mathrm{CO}$ on $\mathrm{Pt} / \mathrm{LTL}$ and $\mathrm{Pt} / \mathrm{SiO}_{2}$

\begin{tabular}{cclc}
\hline catalyst & $\begin{array}{c}\text { linear/bridged } \\
\text { ratio }\end{array}$ & \multicolumn{1}{c}{ catalyst } & $\begin{array}{c}\text { linear/bridged } \\
\text { ratio }\end{array}$ \\
\hline Pt/LTL(0.63) & 3.2 & ${\mathrm{Pt} / \mathrm{SiO}_{2}-\mathrm{Al}(0.10)}_{3}$ & 3.8 \\
Pt/LTL(0.96) & 2.3 & $\mathrm{Pt}_{\mathrm{SiO}}$ & 3.1 \\
Pt/LTL(1.25) & 1.7 & $\mathrm{Pt}_{2} / \mathrm{SiO}_{2}-\mathrm{K}(1.14)$ & 1.1
\end{tabular}

(0.96) is often observed in the IR spectra of Pt/LTL samples and has been assigned to ion-dipole interactions between $\mathrm{K}^{+}$ and adsorbed $\mathrm{CO}^{3}$ The integrated intensity ratio of linear/ bridged $\mathrm{CO}$ decreases with increasing support alkalinity for $\mathrm{Pt} /$ LTL as well as $\mathrm{Pt} / \mathrm{SiO}_{2}$. In other words, $\mathrm{CO}$ prefers bridged to linear coordination with higher support alkalinity.

EXAFS: Influence of CO Adsorption on the Structure of Pt/LTL(0.96). Figure 3 shows the experimental data and Fourier transforms of Pt/LTL(0.96) after reduction and exposure
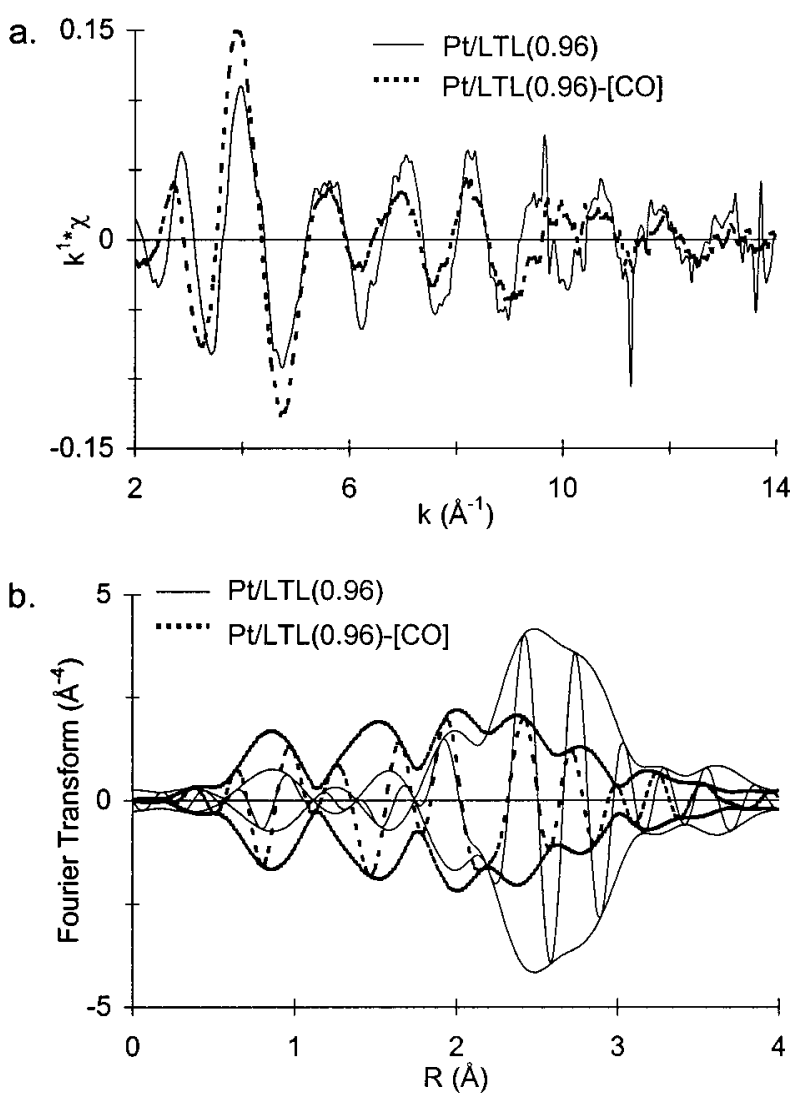

Figure 3. (a) $k^{1}$-weighted experimental data of Pt/LTL(0.96) (solid line) and Pt/LTL(0.96)-[CO] (dotted line), (b) Fourier transform $\left(k^{3}\right.$, $\Delta k=3.2-12.7 \AA^{-1}$ ) of spectra in (a).

to $\mathrm{CO}(\mathrm{Pt} / \mathrm{LTL}(0.96)-[\mathrm{CO}])$. Comparison of the spectra reveals major differences in both the imaginary and absolute parts. Between 0.5 and $2.0 \AA$, the amplitude of the absolute part for $\mathrm{Pt} / \mathrm{LTL}(0.96)-[\mathrm{CO}]$ is greater, while in the region from 2.0 to $3.0 \AA$ the amplitude is lower compared to Pt/LTL(0.96). Also between 0.5 and $2.0 \AA$, the nodes in the imaginary part of the Fourier transform are shifted, indicating that the structure of the platinum particles has been altered.

Comparison of the $k^{3} \mathrm{Pt}-\mathrm{Pt}$ phase-corrected Fourier transforms of Pt/LTL(0.96) and Pt/LTL(0.96)-[CO] taken over 6.0$12.7 \AA^{-1}$, which is dominated by $\mathrm{Pt}-\mathrm{Pt}$ scattering (Figure $4 \mathrm{a}$ ), clearly shows that the average first shell $\mathrm{Pt}-\mathrm{Pt}$ coordination number has decreased upon $\mathrm{CO}$ adsorption. To determine the $\mathrm{Pt}-\mathrm{Pt}$ coordination parameters, the spectrum was first analyzed in $R$-space $(\Delta R: 2.3-3.0 \AA)$ with a $k^{3}$-weighted Fourier transform taken over this limited range in $k$-space $(6.0-12.7$ $\AA^{-1}$ ). Subsequently, the other scatterers were identified and all model parameters were optimized together. The model $\mathrm{Pt}-\mathrm{Pt}$ EXAFS contribution obtained after full optimization is shown in Figure $4 \mathrm{~b}$ together with the total spectrum of Pt/LTL(0.96)[CO]. Thus, the $\mathrm{Pt}-\mathrm{Pt}$ contribution indeed dominates the $k^{3}$ weighted Fourier transform taken from 6 to $12.7 \AA^{-1}$. 

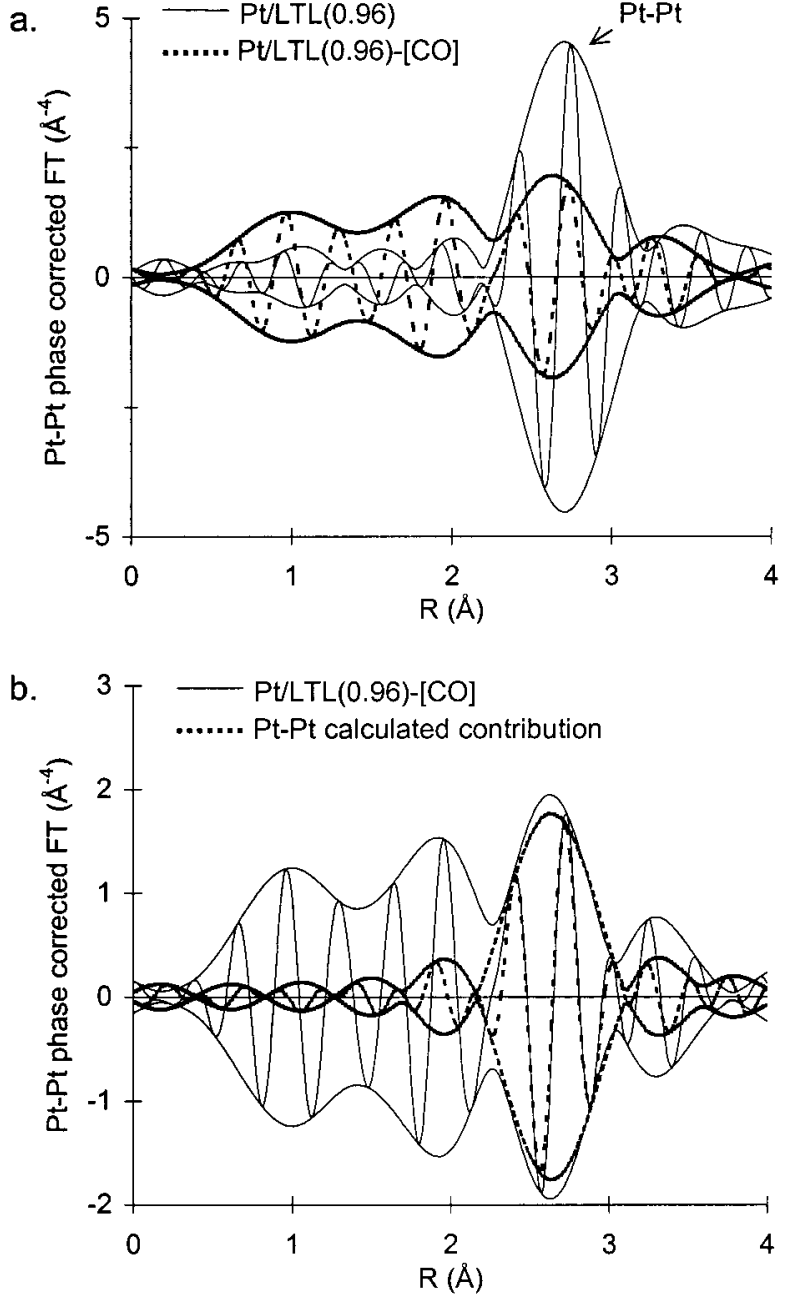

Figure 4. $k^{3}$-weighted, $\mathrm{Pt}-\mathrm{Pt}$ phase corrected Fourier transform $(\Delta k$ $=6.0-12.7 \AA^{-1}$ ) of (a) Pt/LTL $(0.96)$ (solid line) and Pt/LTL $(0.96)$ [CO] (dotted line) and (b) Pt/LTL(0.96)-[CO] (solid line) and calculated $\mathrm{Pt}-\mathrm{Pt}$ contribution (Table 5).

Figure 5 shows the experimental data and Fourier transform of Pt/LTL(0.96)-[CO] together with the model spectrum obtained after analysis in $R$-space (Table 5). Fitting of the spectra in $R$-space ( $k^{1}$ and $k^{3}$ weighted, using different $k$-ranges) reveals $\mathrm{Pt}-\mathrm{Pt}, \mathrm{Pt}-\mathrm{C}, \mathrm{Pt}-\mathrm{O}^{*}$, and $\mathrm{Pt}-\mathrm{O}$ contributions. The resemblance of the experimental data and calculated spectrum in $k$ - and $R$-space (Figure 5a,b) indicates that no additional backscatterers are present. The statistical significance of each contribution was over $85 \%$.

Parts $\mathrm{c}-\mathrm{f}$ of Figure 5 show the individual model contributions $\chi_{i}$ to the residual spectrum $\left(\chi_{\text {experiment }}-\sum_{j=1, j \neq i}^{n} \chi_{j}\right)$. Both the imaginary and absolute parts of the Fourier transforms of the individual components and the residual spectra are in good agreement for all backscatterers. The EXAFS data analysis for $\mathrm{Pt} / \mathrm{LTL}(0.96)-[\mathrm{CO}]$ show that the $\mathrm{Pt}-\mathrm{Pt}$ distance has contracted to $2.67 \AA$, together with a decrease of $\mathrm{Pt}-\mathrm{Pt}$ coordination number from 4.2 to 2.2 after exposure of Pt/LTL(0.96) to CO at room temperature. In addition to these changes in the $\mathrm{Pt}$ coordination parameters, $\mathrm{Pt}-\mathrm{Pt}$ scattering and $\mathrm{Pt}-\mathrm{C}, \mathrm{Pt}-\mathrm{O}$, and $\mathrm{Pt}-\mathrm{O} *$ scattering were also detected.

EXAFS: Influence of Support Acidity/Alkalinity on Structure of Pt/LTL Catalysts after CO Adsorption. The Fourier transforms of the experimental data for all Pt/LTL and Pt/LTL-[CO] samples are shown in Figure 6. It can be seen that for all samples the EXAFS spectrum significantly changed after exposure to $\mathrm{CO}$ at room temperature. To check the influence of $\mathrm{CO}$ exposure on the $\mathrm{Pt}-\mathrm{Pt}$ coordination, the $k^{3}$ weighted Fourier transforms for $\Delta k\left(6.0-12.7 \AA^{-1}\right)$ were compared (Figure 7). For Pt/LTL(0.63)-[CO] and Pt/LTL(1.25)[CO], a decrease in amplitude between 2 and $3 \AA$ is visible, similar to that for Pt/LTL(0.96)-[CO], showing that the $\mathrm{Pt}-\mathrm{Pt}$ coordination has changed. Closer examination of the figure also reveals that the three Pt/LTL-[CO] spectra are clearly different from each other in shape and amplitudes, indicating that the final structure of the platinum particles with $\mathrm{CO}$ is different for each catalyst.

EXAFS: Effect of CO Adsorption on the Structure of Pt/ $\mathrm{SiO}_{2}$ Catalysts. Parts a $-\mathrm{c}$ of Figure 8 show $k^{1}$-weighted Fourier transforms of the experimental data for reduced $\mathrm{Pt} / \mathrm{SiO}_{2}$ together with $\mathrm{Pt} / \mathrm{SiO}_{2}-[\mathrm{CO}]$. For each sample, there are small deviations after exposure to $\mathrm{CO}$. However, shape and position of the imaginary parts do not change upon exposure to $\mathrm{CO}$, indicating that the average local structure of platinum is essentially the same. To evaluate the $\mathrm{Pt}-\mathrm{Pt}$ contribution, $\mathrm{Pt}-\mathrm{Pt}$ phase corrected $k^{3}$-weighted Fourier transforms are compared for $k$ : 6.0-12.7 $\AA^{-1}$ (Figure $8 \mathrm{~d}-\mathrm{f}$ ). The position and shape of the platinum EXAFS signal does not change upon $\mathrm{CO}$ exposure; however, the intensity slightly decreased for $\mathrm{Pt} / \mathrm{SiO}_{2}-\mathrm{Al}(0.10)-[\mathrm{CO}]$ and $\mathrm{Pt} / \mathrm{SiO}_{2}-[\mathrm{CO}]$, while it increased for $\mathrm{Pt} / \mathrm{SiO}_{2}-\mathrm{K}(1.14)-[\mathrm{CO}]$. These changes in intensity can be attributed to differences in coordination number and/or disorder in the $\mathrm{Pt}-\mathrm{Pt}$ contribution. The $R$-space model fits $\left(\Delta R: 1.0-3.5\right.$, optimized in both $k^{1}$ and $k^{3}$ ) of the spectra of $\mathrm{Pt} / \mathrm{SiO}_{2}$-[CO] are reported in Tables 6-8. The Fourier transforms of the model spectra and the experimental data are shown in Figure 9. The spectra agree very well for $R$ : $1.2-3.3 \AA$. The $\mathrm{Pt}-\mathrm{Pt}$ coordination numbers are similar or slightly smaller than those of the reduced catalysts, and moreover, the $\mathrm{Pt}-\mathrm{Pt}$ distances are identical for the samples with and without $\mathrm{CO}$. In addition to $\mathrm{Pt}-\mathrm{Pt}$ coordination, also $\mathrm{Pt}-\mathrm{C}$ and $\mathrm{Pt}-\mathrm{O}^{*}$ could be detected, originating from adsorbed $\mathrm{CO}$.

\section{Discussion}

Structure of Catalysts after Reduction. All catalysts contained metallic platinum particles, as can be concluded from the observed $\mathrm{Pt}-\mathrm{Pt}$ distances that are similar to the $\mathrm{Pt}-\mathrm{Pt}$ distance in Pt-foil (2.77 ̊). The Pt/LTL samples consist of metal particles with the average first shell coordination number smaller than 4.5. Assuming closest packing of Pt atoms, the average metal particle in Pt/LTL contains approximately 4-6 atoms. These small particles easily fit inside the pockets of a zeolite LTL channel. The $\mathrm{Pt} / \mathrm{SiO}_{2}$ catalysts have larger first shell coordination numbers $(N>5)$, and consequently contain more Pt atoms per particle. Assuming a spherical closest packing, the particle sizes range approximately from 15 to 50 atoms, going from $\mathrm{Pt} / \mathrm{SiO}_{2}-\mathrm{K}(1.14)$ to $\mathrm{Pt} / \mathrm{SiO}_{2}-\mathrm{Al}(0.10)$. The very small platinum particles in zeolite LTL are believed to be stabilized by the zeolite geometrical pore structure, which is absent on the $\mathrm{SiO}_{2}$ surface.

In addition, a scattering contribution from the support oxygen atoms could be observed. The long $\mathrm{Pt}-\mathrm{O}$ distance of approximately $2.7 \AA$ for the Pt/LTL samples is in accordance with previous studies on Pt/LTL and is attributed to the presence of interfacial hydrogen after low-temperature reduction. ${ }^{24}$ The short $\mathrm{Pt}-\mathrm{O}$ distance of $2.2 \AA$ for the $\mathrm{Pt} / \mathrm{SiO}_{2}$ catalysts indicates that the $\mathrm{Pt}$ particles are in direct contact with the support oxygen atoms, despite the low $\left(300{ }^{\circ} \mathrm{C}\right)$ reduction temperature. The coordination distance is similar to those in $\mathrm{Ir} / \mathrm{Al}_{2} \mathrm{O}_{3}{ }^{22}$ and $\mathrm{Pt} /$ $\mathrm{Al}_{2} \mathrm{O}_{3}{ }^{25}$ catalysts after high-temperature reduction $\left(>450{ }^{\circ} \mathrm{C}\right)$. 

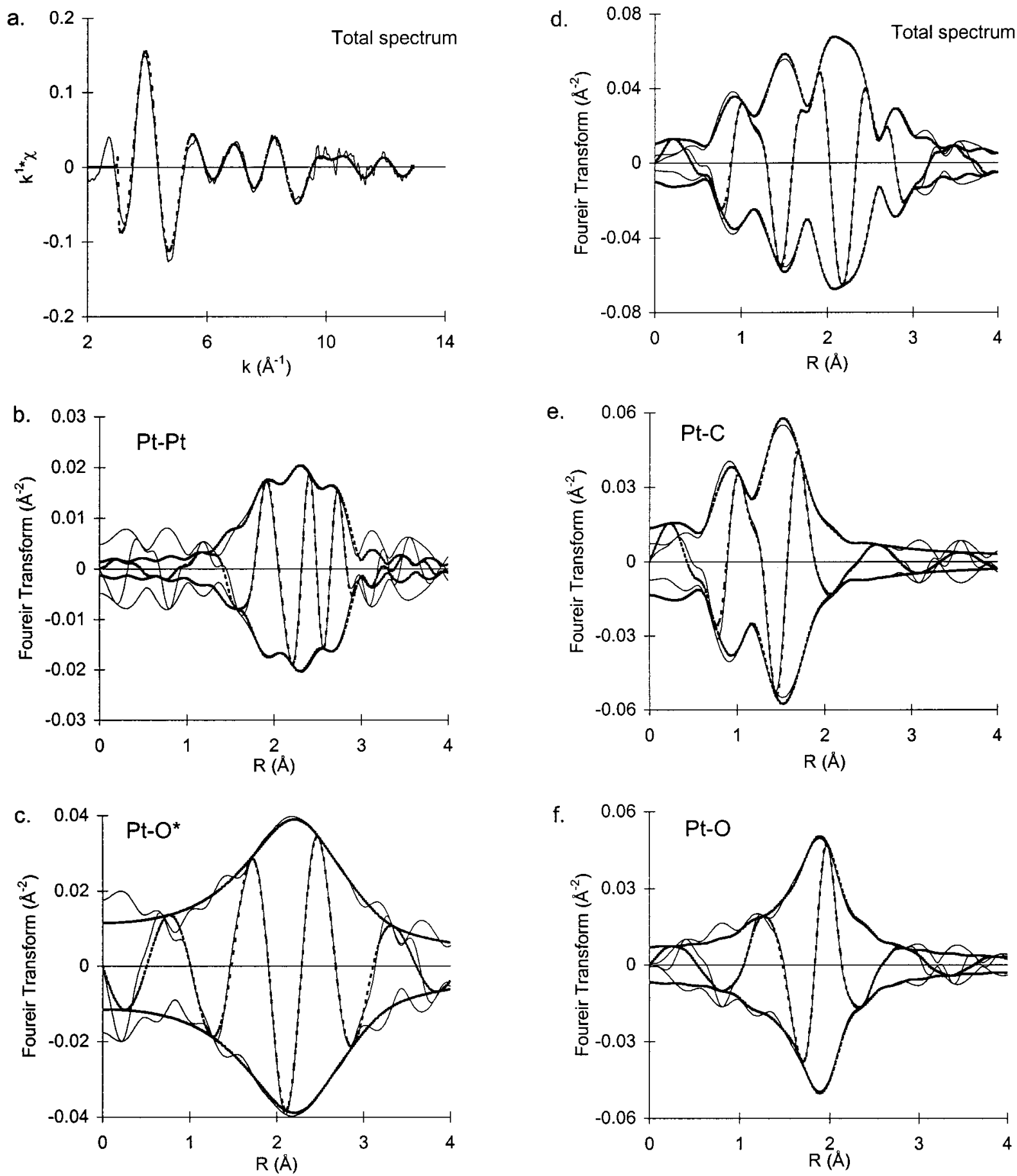

Figure 5. (a) Experimental EXAFS data of Pt/LTL(0.96)-[CO] (solid line) and calculated spectrum with parameters given in Table 6 (dashed line). (b) Fourier transform $\left[k^{1}, \Delta k=3.2-12.7 \AA^{-1}\right]$ of EXAFS data of Pt/LTL $(0.96)-[C O]$ (solid line) and calculated spectrum with parameters given in Table 6 (dashed line). (c) $\mathrm{Pt}-\mathrm{Pt}$ : calculated contribution (dotted line) and EXAFS data minus calculated $[(\mathrm{Pt}-\mathrm{C})+(\mathrm{Pt}-\mathrm{O} *)+(\mathrm{Pt}-\mathrm{O})]($ solid line). (d) $\mathrm{Pt}-\mathrm{C}$ : calculated contribution (dotted line) and EXAFS data minus calculated $[(\mathrm{Pt}-\mathrm{Pt})+(\mathrm{Pt}-\mathrm{O} *)+(\mathrm{Pt}-\mathrm{O})](\mathrm{solid}$ line $)$. (e) $\mathrm{Pt}-\mathrm{O} *$ : calculated contribution (dotted line) and EXAFS data minus calculated $[(\mathrm{Pt}-\mathrm{Pt})+(\mathrm{Pt}-\mathrm{C})+(\mathrm{Pt}-\mathrm{O})]$ ( solid line). (f) $\mathrm{Pt}-\mathrm{O}$ : calculated contribution (dotted line) and EXAFS data minus calculated $[(\mathrm{Pt}-\mathrm{Pt})+(\mathrm{Pt}-\mathrm{C})+(\mathrm{Pt}-\mathrm{O} *)]($ solid line $)$.

The difference in metal-support characteristics between the zeolite and $\mathrm{SiO}_{2}$ supported catalysts can be due to (i) the larger metal particles for $\mathrm{Pt} / \mathrm{SiO}_{2}$ and (ii) the differences in support properties.

Influence of CO Adsorption on Particle Structure of Pt/ LTL. Analysis of Pt/LTL(0.96)-[CO] revealed a contraction of the $\mathrm{Pt}-\mathrm{Pt}$ distance from 2.74 to $2.67 \AA$, accompanied by a decrease in $\mathrm{Pt}-\mathrm{Pt}$ coordination number from 4.5 to 2.2. Both features indicate a reconstruction of the metallic platinum particles ( \pm 6 atoms) into smaller aggregates ( $\pm 3 \mathrm{Pt}$ atoms). The
TABLE 5: Structural Parameters for Pt/LTL(0.96)-[CO], $R$-Space Fit, $\Delta k=3.2-12.7 \AA^{-1}, \Delta R=0.5-4.0 \AA^{a}$

\begin{tabular}{ccccc}
\hline scatterer & $N( \pm 5 \%)$ & $R(\AA)^{b}$ & $\begin{array}{c}\Delta \sigma^{2}\left(10^{-3} \AA^{2}\right) \\
( \pm 5 \%)\end{array}$ & $\begin{array}{c}\Delta E_{0}(\mathrm{eV}) \\
( \pm 10 \%)\end{array}$ \\
\hline $\mathrm{Pt}$ & 2.2 & $2.67 \pm 0.02$ & 4.8 & 12.0 \\
$\mathrm{O}^{*}$ & 2.3 & $2.86 \pm 0.08$ & 19.9 & 1.6 \\
$\mathrm{C}$ & 2.4 & $1.92 \pm 0.02$ & 2.2 & -1.8 \\
$\mathrm{O}$ & 1.3 & $2.28 \pm 0.02$ & 5.5 & -5.8
\end{tabular}

${ }^{a} k^{1}$-variance: absolute part FT, $0.8 \%$; imaginary part FT, $0.3 \%$.

${ }^{b}$ Calculated mathematical errors. 
a.

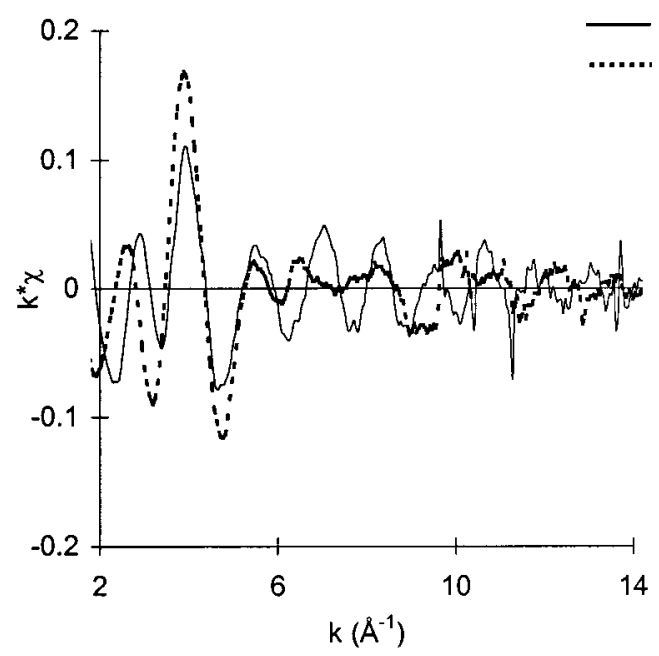

Pt/LTL(0.63)

Pt/LTL(0.63)-[CO]

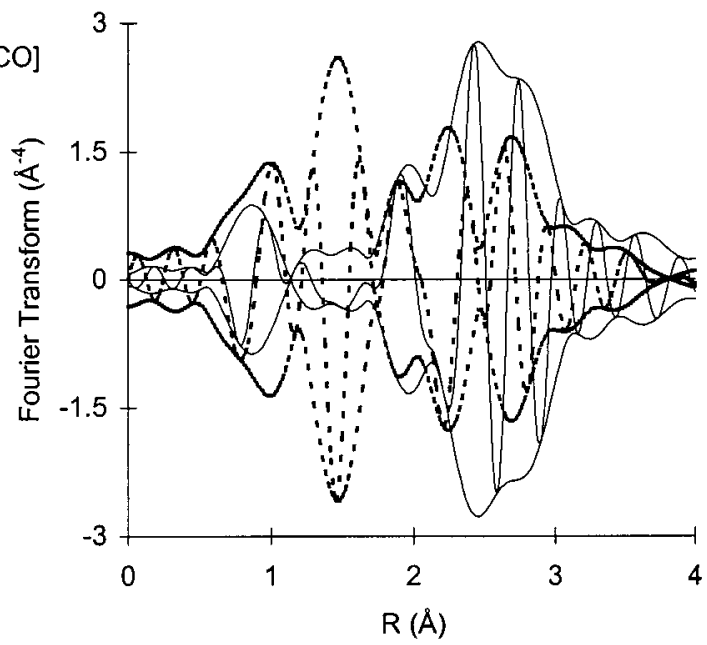

b.

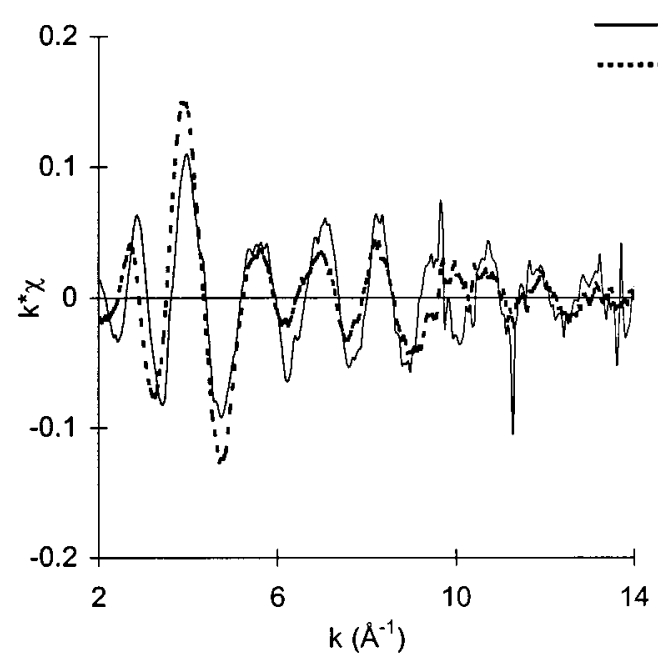

PULTL(0.96)

Pt/LTL(0.96)-[CO]

e.

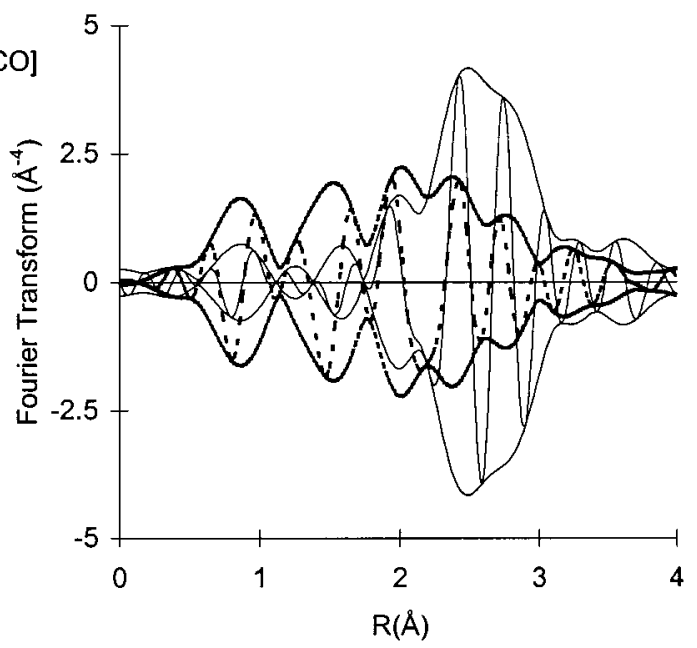

c.
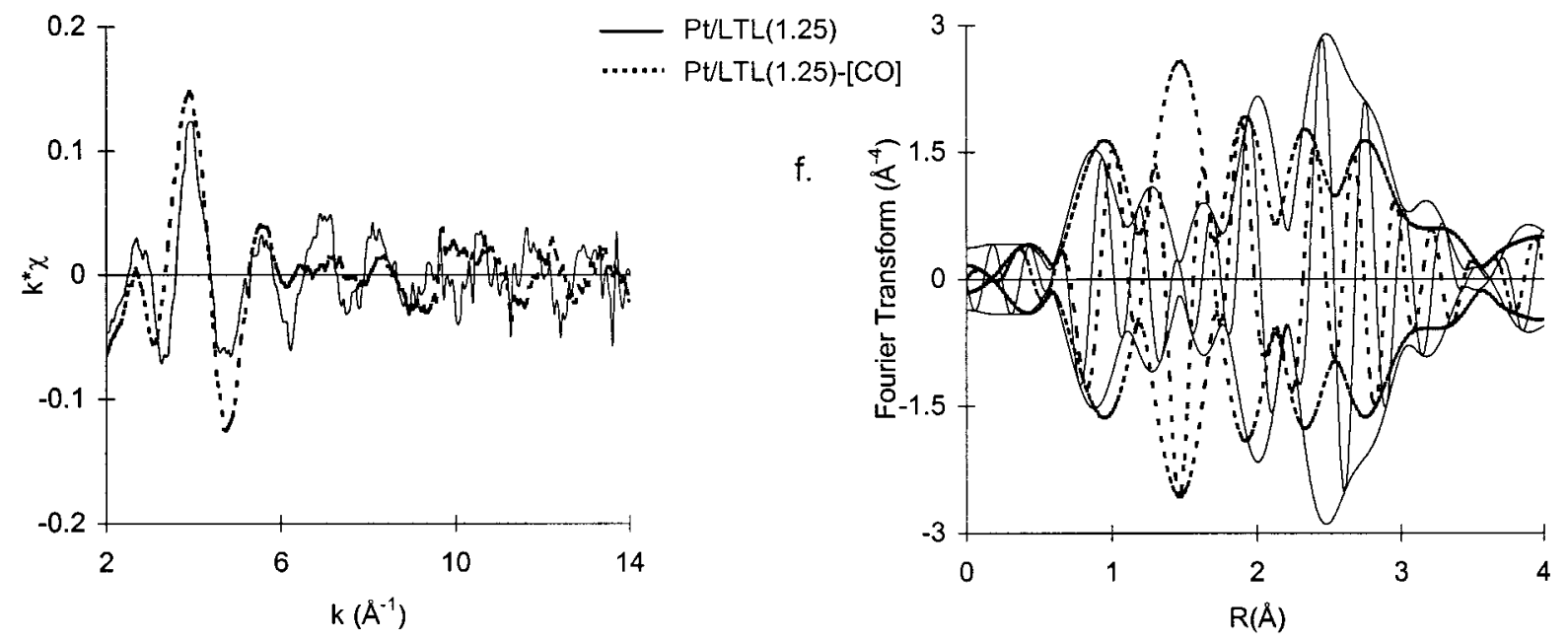

Figure 6. (a)-(c). $k^{1}$-weighted experimental data EXAFS data of Pt/LTL (solid line) with (dotted lines): (a) Pt/LTL(0.63)-[CO]; (b) Pt/LTL(0.96)-[CO]; (c) Pt/LTL(1.25)-[CO]. (d)-(f). Fourier transform $\left(k^{3}, \Delta k: 3.0-12.7 \AA^{-1}\right)$ of spectra in (a)-(c).

inner potential correction $\left(\Delta E_{0}\right)$ of the $\mathrm{Pt}-\mathrm{Pt}$ contribution is quite large compared to reduced Pt/LTL(0.96). This can be due to the difference between the experimental $\mathrm{Pt}-\mathrm{Pt}$ distance $(2.67$ $\AA$ ) and the reference compound (Pt foil, $2.77 \AA$ ) or a change in electronic structure of platinum upon adsorption of CO. Further, the $\mathrm{Pt}-\mathrm{C}$ and $\mathrm{Pt}-\mathrm{O} *$ contributions show that $\mathrm{CO}$ molecules coordinated to $\mathrm{Pt}$ are present. The difference in distance of $\sim 1$ $\AA$ between $\mathrm{C}$ and $\mathrm{O} *$ is in good agreement with the intramolecular distance in $\mathrm{CO}(1.1 \AA) ;{ }^{22}$ however, the error in distance for the $\mathrm{Pt}-\mathrm{O}^{*}$ contribution is larger than for the other 
a.

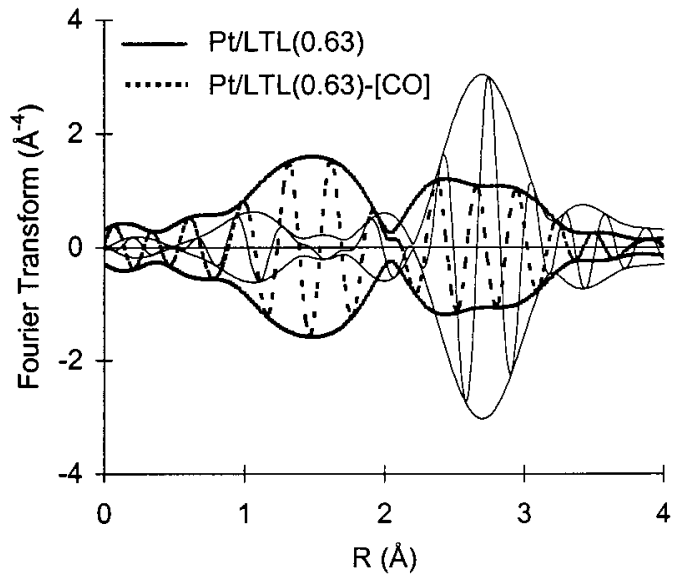

b.

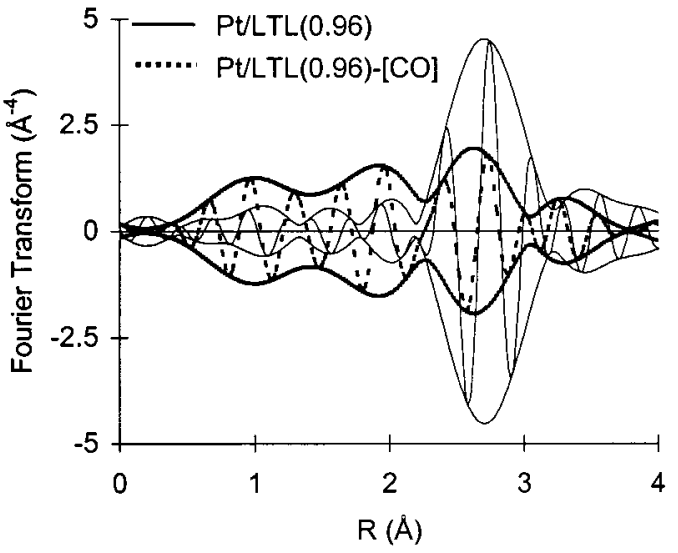

c.

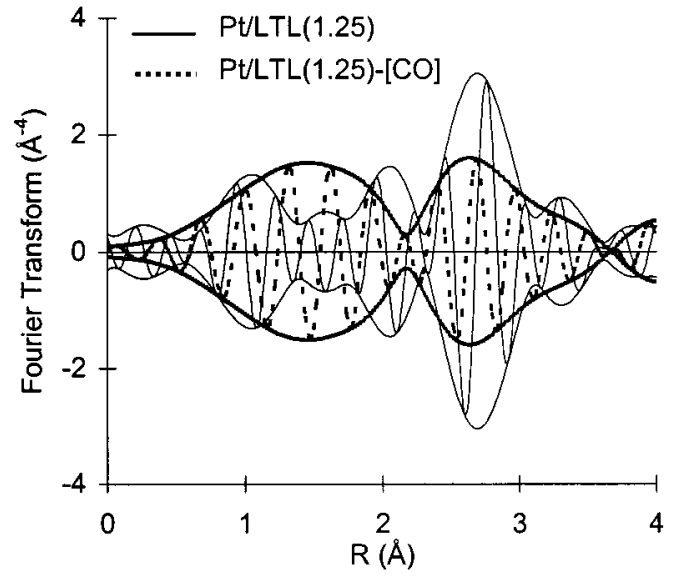

Figure 7. $k^{3}$-weighted, $\mathrm{Pt}-\mathrm{Pt}$ phase corrected Fourier transform $(\Delta k$ $=6.0-12.7 \AA^{-1}$ ) of Pt/LTL (solid line) with (dotted lines): (a) Pt/ LTL(0.63)-[CO]; (b) Pt/LTL(0.96)-[CO]; (c) Pt/LTL(1.25)-[CO].

contributions. In addition, the large Debye-Waller factor of $19.9 \times 10^{-3} \AA^{2}$ indicates a higher disorder in the $\mathrm{Pt}-\mathrm{O}^{*}$ backscattering function, which may be due to the fact that bound $\mathrm{CO}$ on a very small platinum entity can bend freely, creating a larger deviation in the average $\mathrm{Pt}-\mathrm{O}^{*}$ distance. Moreover, the analysis of the multiple scattering oxygen $\left(\mathrm{O}^{*}\right)$ contribution is based on a reference made for a linear coordinated $\mathrm{CO}$. Linear coordination will lead to the maximum multiple backscattering amplitude for $\mathrm{Pt}-\mathrm{O}^{*}$. As soon as the angle between $\mathrm{O}^{*}-\mathrm{C}-$ $\mathrm{Pt}$ becomes less than $180^{\circ}$, the $\mathrm{Pt}-\mathrm{O}^{*}$ coordination number and distance as detected with XAFS data analysis will be smaller. The FTIR spectra of Pt/LTL(0.96)-[CO] already showed bridged CO. Since the EXAFS data were calculated assuming only linearly coordinated $\mathrm{CO}$, this results in the higher uncertainty of the $\mathrm{Pt}-\mathrm{O}^{*}$ distance. Inclusion of both linearly and bridged coordinated $\mathrm{CO}$ in the EXAFS analysis was not statistically justified.

The fourth contribution at $2.28 \AA$ in the Fourier transform is most likely due to support oxygen atoms. An attempt to fit this contribution with a $\mathrm{Pt}-\mathrm{C}$ coordination resulted in a lowered goodness of fit. Furthermore, if there was a $\mathrm{Pt}-\mathrm{C}$ contribution at $2.28 \AA$, there also should be a significant $\mathrm{Pt}-\mathrm{O}^{*}$ contribution at around 3.0-3.4 $\AA$. However, no O* contribution could be detected in the region 3.0-3.4 $\AA$. Recently, based on FTIR experiments, it was suggested that neutral carbonyl complexes were formed from platinum in zeolite LTL upon exposure to $\mathrm{CO}^{8}{ }^{8}$ The FTIR spectra in that study significantly differed from those of negatively charged Chini complexes. ${ }^{26}$ The $\mathrm{Pt}-\mathrm{Pt}$ coordination number (2.2) and distance $(2.67 \AA)$ determined in the present study for Pt/LTL(0.96)-[CO] are similar to those in an anionic Chini complex $\left(\left[\mathrm{Pt}(\mu \mathrm{CO})(\mathrm{CO})_{2}\right]_{n}{ }^{2-}\right)\left(N_{\mathrm{Pt}-\mathrm{Pt}}=2, R\right.$ $=2.64 \AA$ ) ${ }^{27}$ However, the numbers of CO ligands (average of 2.4 for $\mathrm{Pt} / \mathrm{LTL}(0.96)-[\mathrm{CO}])$ are not alike, since in a Chini complex each $\mathrm{Pt}$ atom is surrounded by three carbon atoms (two bridged bound, one linear coordinated). Furthermore, the FTIR spectrum of $\mathrm{Pt} / \mathrm{LTL}(0.96)-[\mathrm{CO}]$ is also different from that of Chini complexes. ${ }^{26}$ First, the spectrum of a Chini complex shows a linear and a bridged absorption band with almost the same absorption intensity, while the $\mathrm{L} / \mathrm{B}$ ratio of Pt/LTL(0.96)-[CO] is much greater than 1 . Second, the infrared absorption band of bridged $\mathrm{CO}$ in the Chini complex is located at around 1750 $\mathrm{cm}^{-1}$, which is $80 \mathrm{~cm}^{-1}$ lower than bridged $\mathrm{CO}$ on Pt/LTL(0.96).

The EXAFS and FTIR data clearly demonstrate that CO adsorption on Pt/LTL(0.96) results in a decrease of the metal particle size, but an aggregate has formed that is different from a Chini complex, as suggested in ref 8. Interestingly, the $\mathrm{Pt}-$ $\mathrm{O}_{\text {support }}$ contribution in the EXAFS data suggests that not only is the three-atom platinum cluster stabilized by CO ligands as in a Chini complex but also the support has an active role in stabilizing the $\mathrm{Pt}-\mathrm{CO}$ aggregate. To visualize this, Figure 10 depicts a possible structure of $\mathrm{Pt} / \mathrm{LTL}(0.96)-[\mathrm{CO}]$. The $\mathrm{Pt}-\mathrm{Pt}$ distance of $2.67 \AA$ and $\mathrm{Pt}-\mathrm{O}$ distance of $2.28 \AA$ taken into account point to a cluster that fits exactly in the small LTLpore opening of $7.1 \AA$. In Figure 10 , the coordination of $\mathrm{CO}$ to platinum has a L/B ratio of 3 , found in the FTIR data, and a $\mathrm{Pt}-\mathrm{C}$ coordination number of 2 , which is close to 2.4 as determined by XAFS spectroscopy. Of course, other geometries of the $\mathrm{Pt}-\mathrm{CO}$ cluster inside the zeolite pore are possible as well; nevertheless, the good agreement between the size of the $\mathrm{Pt}-\mathrm{CO}$ aggregate and the zeolite LTL pore and the presence of a significant $\mathrm{Pt}-\mathrm{O}_{\text {support }}$ scattering strongly suggest that the cluster is stabilized by coordination with the zeolite walls.

Comparison of Pt/LTL(0.63)-[CO] and Pt/LTL(1.25)-[CO] with Pt/LTL(0.96)-[CO] in a Pt-Pt emphasized plot (Figure 7) demonstrated that for all catalysts the $\mathrm{Pt}-\mathrm{Pt}$ contribution decreased after exposure to $\mathrm{CO}$, indicating that the metal particles reconstructed to smaller aggregates for each sample. However, Figures 6 and 7 also show that each sample has a different XAFS spectrum after $\mathrm{CO}$ adsorption. Main differences are manifest below $2 \AA$ and above $2.8 \AA$, where $\mathrm{Pt}-\mathrm{C}$ and $\mathrm{Pt}-$ $\mathrm{O} *$ contribute significantly, strongly suggesting that the geometry of the coordination of $\mathrm{CO}$ to the metal atoms depends on the zeolite acidity. It was not possible to fully analyze the EXAFS spectra of Pt/LTL(0.63)-[CO] and Pt/LTL(1.25)-[CO] due to the different ratio of linear/bridged CO. It is further not possible to arrive at a unique model describing the EXAFS data, 


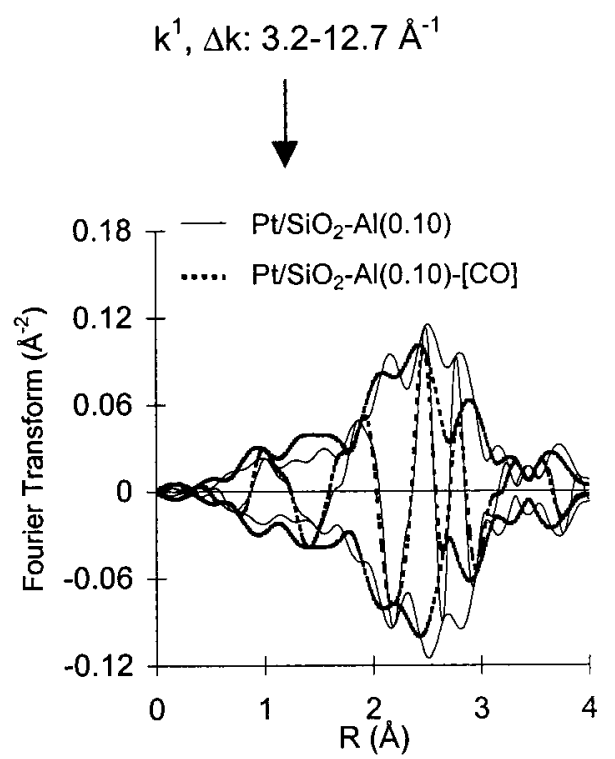

$\mathrm{k}^{3}, \Delta \mathrm{k}: 6.0-12.7 \AA^{-1}$

Pt-Pt phase corrected
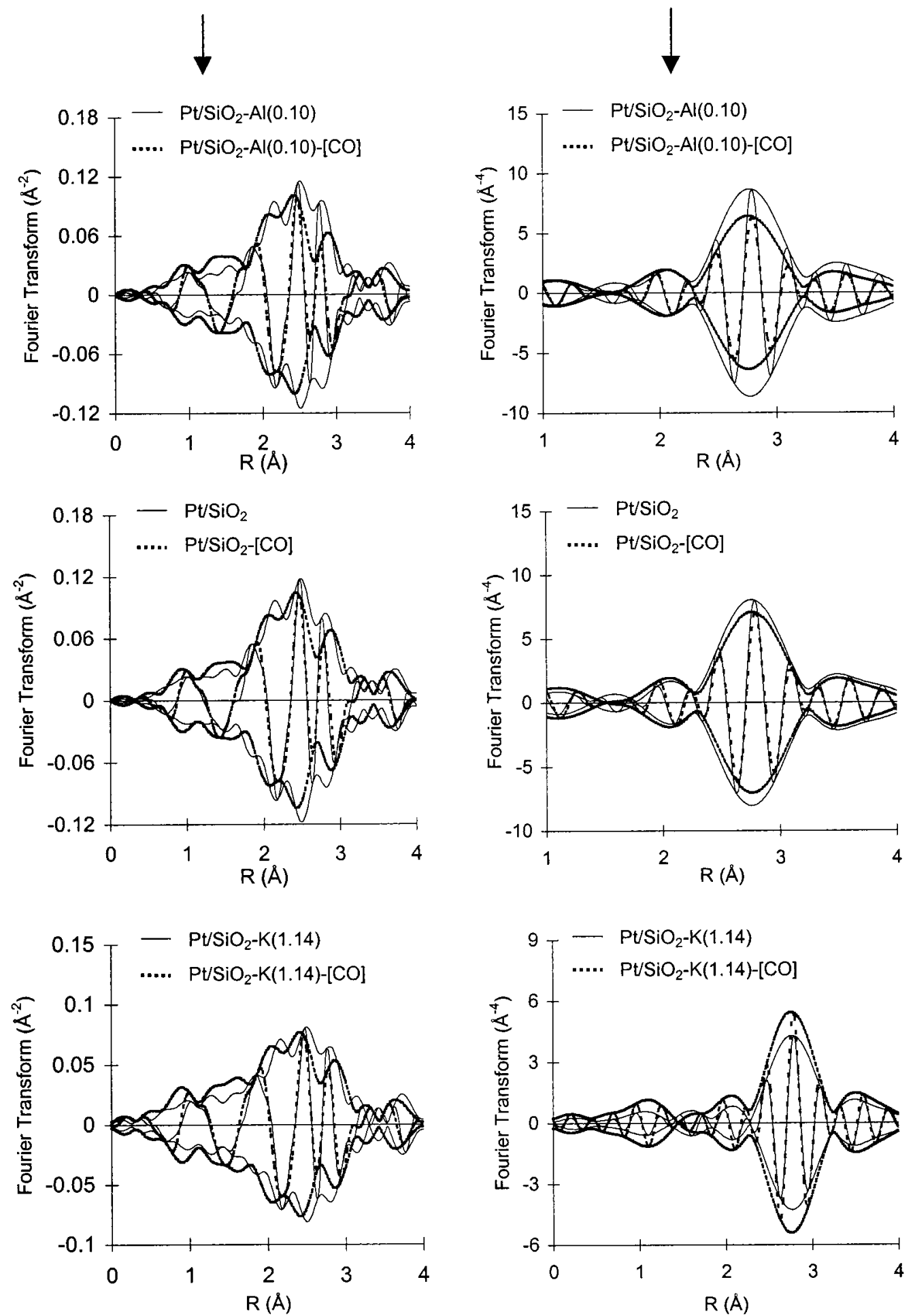

Figure 8. (a)-(c). $k^{1}$-weighted Fourier transform $\left(\Delta k=3.2-12.7 \AA^{-1}\right)$ of experimental data $\mathrm{EXAFS}$ data of $\mathrm{Pt} / \mathrm{SiO}_{2}(\mathrm{solid}$ line $)$ with $\mathrm{Pt} / \mathrm{SiO}_{2}{ }^{-}$ [CO] (dotted line): (a) $\mathrm{Pt} / \mathrm{SiO}_{2}-\mathrm{Al}(0.10)$; (b) $\mathrm{Pt} / \mathrm{SiO}_{2}$; (c) $\mathrm{Pt} / \mathrm{SiO}_{2}-\mathrm{K}(1.14)$. (d) - (f) $k^{3}$-weighted $\mathrm{Pt}-\mathrm{Pt}$ phase corrected Fourier transform $(\Delta k=$ 6.0-12.7 $\AA^{-1}$ ) of same samples.

since (i) the available data range is limiting the number of free parameters and (ii) the $\mathrm{Pt}-\mathrm{O}^{*}$ contribution is strongly interfering with the Pt-Pt EXAFS. Still, EXAFS showed a change in platinum coordination upon $\mathrm{CO}$ adsorption that is different for each support applied. This observation is in line with the FTIR spectra, since these data also showed different sample absorption patterns with changing support acidity.
Influence of CO Adsorption on the Particle Structure of $\mathbf{P t} / \mathrm{SiO}_{2}$. The platinum particles supported on $\mathrm{SiO}_{2}$ show much smaller changes upon exposure to $\mathrm{CO}$ in comparison with the $\mathrm{Pt} / \mathrm{LTL}$ samples. The platinum-platinum coordination numbers and distances are only slightly smaller than those of the reduced catalysts measured under hydrogen. In addition to the $\mathrm{Pt}-\mathrm{Pt}$ contribution, carbon and oxygen scattering (arising from the 
TABLE 6: Structural Parameters for $\mathrm{Pt} / \mathrm{SiO}_{2}-\mathrm{Al}(0.10)-[\mathrm{CO}]$, $R$-space Fit, $\Delta k=3.1-12.8 \AA^{-1}, \Delta R=1.0-3.5 \AA^{a}$

\begin{tabular}{ccccc}
\hline scatterer & $N( \pm 5 \%)$ & $R(\AA)^{b}$ & $\begin{array}{c}\Delta \sigma^{2}\left(10^{-3} \AA^{2}\right) \\
( \pm 5 \%)\end{array}$ & $\begin{array}{c}\Delta E_{0}(\mathrm{eV}) \\
( \pm 10 \%)\end{array}$ \\
\hline $\mathrm{Pt}$ & 6.8 & $2.77 \pm 0.03$ & 3.4 & 2.4 \\
$\mathrm{O}^{*}$ & 1.1 & $2.85 \pm 0.03$ & 11.4 & 3.9 \\
$\mathrm{C}$ & 0.9 & $1.85 \pm 0.02$ & -0.4 & 6.7
\end{tabular}

${ }^{a} k^{1}$-variance: absolute part FT, $1.3 \%$; imaginary part FT, $0.4 \%$. ${ }^{b}$ Calculated mathematical errors.

TABLE 7: Structural Parameters for $\mathbf{P t} / \mathrm{SiO}_{2}$-[CO], $R$-Space Fit, $\Delta k=3.1-12.8 \AA^{-1}, \Delta R=1.0-3.5 \AA^{a}$

\begin{tabular}{ccccc}
\hline scatterer & $N( \pm 5 \%)$ & $R(\AA)^{b}$ & $\begin{array}{c}\Delta \sigma^{2}\left(10^{-3} \AA^{2}\right) \\
( \pm 5 \%)\end{array}$ & $\begin{array}{c}\Delta E_{0}(\mathrm{eV}) \\
( \pm 10 \%)\end{array}$ \\
\hline $\mathrm{Pt}$ & 7.3 & $2.77 \pm 0.03$ & 3.1 & 2.5 \\
$\mathrm{O}^{*}$ & 1.0 & $2.84 \pm 0.03$ & 10.7 & 3.6 \\
$\mathrm{C}$ & 1.0 & $1.84 \pm 0.02$ & 1.0 & 11.8
\end{tabular}

${ }^{a} k^{1}$-variance: absolute part FT, $1.0 \%$; imaginary part FT, $0.5 \%$. ${ }^{b}$ Calculated mathematical errors.

TABLE 8: Structural Parameters for $\mathrm{Pt} / \mathrm{SiO}_{2}-\mathrm{K}(1.14)-[\mathrm{CO}]$, $R$-Space Fit, $\Delta k:=3.1-12.8 \AA^{-1}, \Delta R=1.0-3.5 \AA^{a}$

\begin{tabular}{ccccc}
\hline scatterer & $N( \pm 5 \%)$ & $R(\AA)^{b}$ & $\begin{array}{c}\Delta \sigma^{2}\left(10^{-3} \AA^{2}\right) \\
( \pm 5 \%)\end{array}$ & $\begin{array}{c}\Delta E_{0}(\mathrm{eV}) \\
( \pm 10 \%)\end{array}$ \\
\hline $\mathrm{Pt}$ & 5.1 & $2.77 \pm 0.03$ & 2.7 & 1.0 \\
$\mathrm{O}^{*}$ & 0.8 & $2.89 \pm 0.03$ & 12.5 & 3.5 \\
$\mathrm{C}$ & 1.7 & $1.84 \pm 0.02$ & 6.2 & 15.4
\end{tabular}

${ }^{a} k^{1}$-variance Absolute Part FT: $0.9 \%$, Imaginary Part FT: $0.5 \%$. ${ }^{b}$ Calculated mathematical errors.

CO molecule) was detected. The $\mathrm{Pt}-\mathrm{O} *$ contributions had high Debye-Waller factors, similar to those of Pt/LTL(0.96)-[CO]. The distance between carbon and oxygen was also around 1.0 $\AA$, which is in accordance with the intramolecular distance in $\mathrm{CO}$ and similar to the $\mathrm{C}-\mathrm{O}$ distance for Pt/LTL(0.96)-[CO].

The ratio of the $\mathrm{Pt}-\mathrm{C} / \mathrm{Pt}-\mathrm{O} *$ coordination numbers steadily increased with rising support alkalinity (Tables 6-8), due to increasing $\mathrm{Pt}-\mathrm{C}$ coordination number as well as decreasing $\mathrm{Pt}-$ $\mathrm{O} *$ scattering intensity. Both observations point to increasing amounts of $\mathrm{CO}$ in bridged coordination in agreement with the FTIR spectra of these samples. The platinum-support oxygen distance could not reliably be detected in the $\mathrm{Pt} / \mathrm{SiO}_{2}-[\mathrm{CO}]$ samples, likely due to the $\mathrm{Pt}-\mathrm{C}$ contribution at $1.84 \AA$, which is much larger than the $\mathrm{Pt}-\mathrm{O}_{\text {support }}$ contribution.

Consequences for Application of CO-FTIR as a Catalyst Characterization Tool. Several studies have shown differences in the reactivity of small supported metal clusters toward CO. Already in 1978, Primet showed that at liquid nitrogen temperature $\mathrm{CO}$ adsorbed onto small supported rhodium particles, while warming to room temperature under $\mathrm{CO}$ led to the formation of geminal dicarbonylrhodium species. ${ }^{28}$ The structure was later confirmed by EXAFS. ${ }^{13}$ It was also shown for rhodium that only very small rhodium metal clusters reconstructed upon $\mathrm{CO}$ exposure, while larger clusters were stable. ${ }^{15}$ On the other hand, for small palladium particles in zeolite $\mathrm{Y}$, upon adsorption of $\mathrm{CO}$, the metal particles produced a large $\mathrm{Pd}_{x}(\mathrm{CO})_{y}$ cluster, just fitting inside the supercages. ${ }^{29}$ In this study, the platinum particles in zeolite LTL undergo reconstruction and decrease in size when exposed to $\mathrm{CO}$ at room temperature. In a different paper we show that this reconstruction of platinum in LTL(0.96) is temperature dependent. ${ }^{30}$ For the larger particles of the $\mathrm{Pt} / \mathrm{SiO}_{2}$ samples, however, little change occurs in the metal particle on $\mathrm{CO}$ adsorption. The effect of particle size on the reactivity of the Pt atoms can be understood from the point of view that, in zeolite LTL, particles merely consist of a single
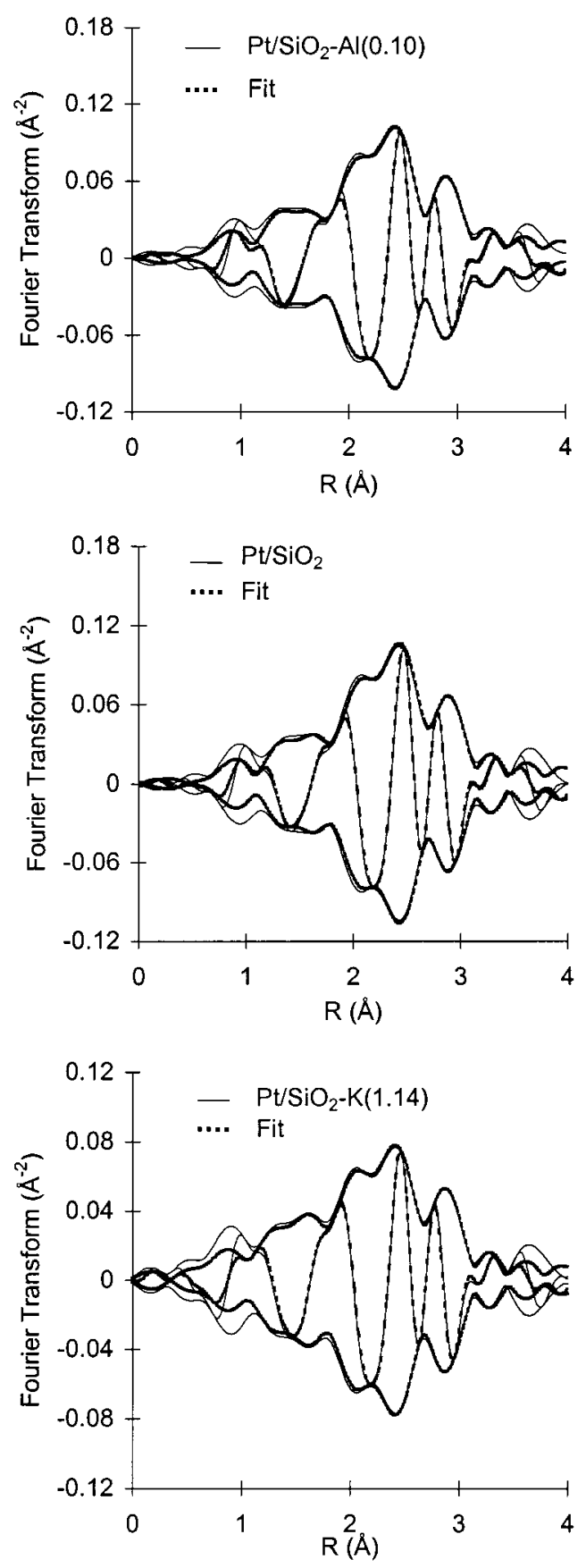

Figure 9. Fourier transform $\left[k^{1}, \Delta k=3.2-12.7 \AA^{-1}\right]$ of EXAFS data of $\mathrm{Pt} / \mathrm{SiO}_{2}-[\mathrm{CO}]$ (solid line) and calculated spectra with parameters given in Tables 6-8 (dashed lines): (a) $\mathrm{Pt} / \mathrm{SiO}_{2}-\mathrm{Al}(0.10)$-[CO]; (b) $\mathrm{Pt} / \mathrm{SiO}_{2-}$ [CO]; (c) $\mathrm{Pt} / \mathrm{SiO}_{2}-\mathrm{K}(1.14)-[\mathrm{CO}]$.

shell coordination of platinum atoms. Consequently, the Pt atoms have a lower cohesive energy and thus show increased reactivity. In line with this, metal particles supported on silica are much more stable, since they consist of several shells of platinum atoms, which increases the cohesive energy and decreases the reactivity. Recently, a paper was published on DFT calculations and microcalorimetric investigations of $\mathrm{CO}$ adsorption on $\mathrm{Pt}$ clusters. ${ }^{31}$ The authors calculated the heat of formation of neutral $\mathrm{Pt}-\mathrm{CO}$ clusters from a 10 -atom Pt cluster to be only $-30 \mathrm{~kJ} /$ mol CO, which is only slightly endothermic. The particles in zeolite LTL consist on average of less than 10 atoms; thus the reaction might even be exothermic for these small clusters. In addition, they suggested that the decomposition of Pt particles of 10 atoms could be $\mathrm{CO}$ pressure dependent, as was suggested 
Front view

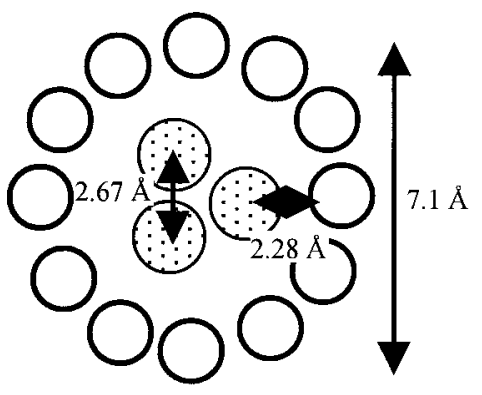

Side view

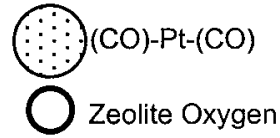

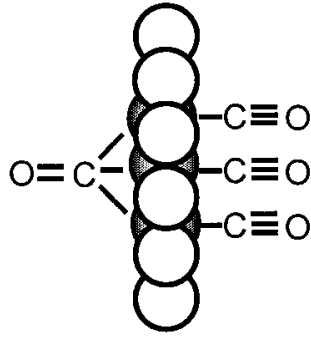

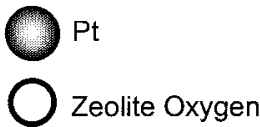

Figure 10. Tentative structure of Pt/LTL(0.96) exposed to CO.

earlier by Stakheev et al. ${ }^{8}$ However, since in this study the reactivity toward $\mathrm{CO}$ was determined at $1 \mathrm{~atm} \mathrm{CO}$ pressure for all samples, the stable metal particles on $\mathrm{SiO}_{2}$ can only be explained by the fact that the particles are larger and consequently more stable.

A particle size dependent reactivity of platinum particles toward $\mathrm{CO}$ also explains the slightly decreasing $\mathrm{Pt}-\mathrm{Pt}$ coordination number $(\sim 10 \%)$ for the $\mathrm{Pt} / \mathrm{SiO}_{2}$ samples. In addition to the larger average metal particle size, it is likely that there is a particle size distribution. If exclusively very small particles reconstruct upon $\mathrm{CO}$ exposure, then only a small fraction of the $\mathrm{Pt} / \mathrm{SiO}_{2}$ particles will be affected, causing a slight decrease in the average $\mathrm{Pt}-\mathrm{Pt}$ coordination number. An additional aspect of the different behavior of platinum particles on zeolite LTL and $\mathrm{SiO}_{2}$ could be the stabilizing effect of the support material on the newly formed metal-CO clusters, as was suggested for palladium in zeolite $\mathrm{Y}^{29}$

We have previously shown that there is a decrease in the integrated intensity ratio linear/bridged coordinated $\mathrm{CO}$ as well as in the neopentane turnover frequency (TOF) with rising support alkalinity for $\mathrm{Pd} / \mathrm{LTL}, \mathrm{Pt} / \mathrm{LTL}$, and $\mathrm{Pt} / \mathrm{SiO}_{2}$ catalysts. ${ }^{5,6}$ The correlation of the linear-to-bridged ratio with TOF was thought to reflect the changes in the electronic structure of the surface platinum atoms in the catalysts. However, the correlation between CO-FTIR and catalysis is not straightforward. The present study demonstrates that the structure of the platinum particles in LTL zeolite probed by FTIR of adsorbed CO are smaller than those of reduced $\mathrm{Pt}$, which are responsible for catalysis. Interestingly, although there has been significant reconstruction, the linear-to-bridged ratio does seem to reflect the changes in electronic properties induced by the support. Recently, this was confirmed by the position of the $\mathrm{Pt}-\mathrm{H}$ antibonding state relative to the Fermi level as a function of support acidity of the reduced Pt/LTL catalysts. ${ }^{32}$

For $\mathrm{Pt} / \mathrm{SiO}_{2}$ catalysts, $\mathrm{CO}$ adsorption has a much smaller effect on the platinum structure due to the larger metal particles. The $\mathrm{L} / \mathrm{B}$ ratio, in this case, better reflects the changes in electronic properties of the surface metal atoms. As a result, the correlation of $\mathrm{L} / \mathrm{B}$ ratio with $\mathrm{TOF}$ is better for the $\mathrm{Pt} / \mathrm{SiO}_{2}$ catalysts than for Pt/LTL.

\section{Conclusion}

Application of CO-FTIR for determination of the electronic structure (reflected in L/B ratio) has to be done with care. Special attention has to be paid with regard to metal particle size. The present study demonstrates that larger platinum

particles (i.e., $N_{\text {first shell }}>5$ ) on $\mathrm{SiO}_{2}$ are stable to exposure of $\mathrm{CO}$ at room temperature. Smaller particles, supported on zeolite LTL, however, form $\mathrm{Pt}-\mathrm{CO}$ aggregates after admission of $\mathrm{CO}$.

Although XAFS indicates that $\mathrm{CO}$ adsorption results in the formation of smaller metal particles, the correlation with the TOF suggests that the linear-to-bridged ratio is primarily affected by the electronic properties of the Pt particles. In addition, the decrease in $\mathrm{L} / \mathrm{B}$ ratio with increasing support alkalinity is strong evidence that the support composition induces changes in the electronic properties of the metal particles that, in turn, lead to modification of the catalytic activity.

\section{References and Notes}

(1) Kappers, M. J.; Miller, J. T.; Koningsberger, D. C. J. Phys. Chem. 1996, 100, 3227

(2) van Hardeveld, R.; Hartog, F. Adv. Catal. 1972, 22, 75.

(3) Kappers, M. J.; Vaarkamp, M.; Miller, J. T.; Modica, F. S.; van der Maas, J. H.; Koningsberger, D. C. Catal. Lett. 1993, 21, 235.

(4) Stoop, F.; Toolenaar, F. J. C. M.; Ponec, V. J. Catal. 1982, 73, 50.

(5) Mojet, B. L.; Kappers, M. J.; Muijsers, J. C.; Niemantsverdriet, J. W.; Miller, J. T.; Modica, F. S.; Koningsberger, D. C. Stud. Surf. Sci. Catal. 1994, 84, 909.

(6) Mojet, B. L.; Kappers, M. J.; Miller, J. T.; Koningsberger, D. C. Stud. Surf. Sci. Catal. 1996, 101, 1165.

(7) van Santen, R. A. J. Chem. Soc., Faraday Trans. 1 1987, 8, 1915.

(8) Stakheev, A. Yu.; Shpiro, E. S.; Jaeger, N. I.; Schulz-Ekloff, G. Catal. Lett. 1995, 34, 293.

(9) de Mallmann, A.; Barthomeuf, D. Catal. Lett. 1990, 5, 293.

(10) Bischoff, H.; Jaeger, N. I.; Schulz-Ekloff, G.; Kubelkove, L. J. Mol. Catal. 1993, 80, 95

(11) Chang, J.-R.; Xu, Z.; Purnell, S. K.; Gates, B. C. J. Mol. Catal. 1993, 80, 49.

(12) Li, G.-J.; Fujimoto, T.; Fukuoka, A.; Ichikawa, M. Catal. Lett. 1992, 12,171 .

(13) van't Blik, H. F. J.; van Zon, J. B. A. D.; Huizinga, T.; Vis, J. C.; Koningsberger, D. C.; Prins, R. J. Phys. Chem. 1983, 87, 2264.

(14) Koningsberger, D. C.; van 't Blik, H. F. J.; van Zon, J. B. A. D.; Prins, R. Proc. Int. Congr. Catal., 8th 1984, 5, 120.

(15) van't Blik, H. F. J.; van Zon, J. B. A. D.; Koningsberger, D. C.; Prins, R. J. Mol. Catal. 1984, 25, 379.

(16) de Mallmann, A.; Barthomeuf, D. Stud. Surf. Sci. Catal. 1989, 46 429

(17) Vaarkamp, M.; Mojet, B. L.; Kappers, M. J.; Miller, J. T.; Koningsberger, D. C. J. Phys. Chem. 1995, 99, 16067.

(18) Hayes, T. M.; Boyce, J. B. Solid State Phys. 1982, 237, 283

(19) Duivenvoorden, F. B. M.; Koningsberger, D. C.; Uh, Y. S.; Gates, B. C. J. Am. Chem. Soc. 1986, 108, 6254.

(20) Koningsberger, D. C. In Neutron and Synchrotron Radiation for Condensed Matter Studies, Vol. II, Applications to Solid State Physics and Chemistry; Baruchel, J., Hodeau, J. L., Lehmann, M. S., Regnard, J. R., Schlenker, C., Eds.; Springer-Verlag: Berlin, 1994; pp 213-244.

(21) Kampers, F. W. H.; Engelen, C. W. R.; van Hooff, J. H. C.; Koningsberger, D. C. J. Phys. Chem. 1990, 94, 8574.

(22) van Zon, F. B. M.; Maloney, S. D.; Gates, B. C.; Koningsberger,

D. C. J. Am. Chem. Soc. 1993, 115, 10317.

(23) Vaarkamp, M.; Modica, F. S.; Miller, J. T.; Koningsberger, D. C. J. Catal. 1993, 144, 611.

(24) Koningsberger, D. C.; Vaarkamp, M.; Muñoz Paez, A.; van Zon, F. B. M. Iwasawa, Y., Ed.; In X-ray absorption fine structure for catalysts and surfaces; World Scientific: London, 1996; Vol. 2, pp 257-272.

(25) Vaarkamp, M.; Miller, J. T.; Modica, F. S.; Koningsberger, D. C. J. Catal. 1996, 163, 294.

(26) Schulz-Ekloff, G.; Lipski, R. J.; Jaeger, N. I.; Hulstede, P. Catal. Lett. 1995, 30, 65.

(27) Li, G. J.; Fujimoto, T.; Fukuoka, A.; Ichikawa, M. J. Chem. Soc., Chem. Commun. 1991, 1337.

(28) Primet, M. J. Chem. Soc., Faraday Trans. 1 1978, 74, 2570.

(29) Sheu, L. L.; Knozinger, H.; Sachtler, W. M. H. J. Am. Chem. Soc. 1989, 111,8125 .

(30) Mojet, B. L.; de Vooys, A. C. A.; Koningsberger, D. C. Manuscript in preparation.

(31) Watwe, R. M.; Spiewak, B. E.; Cortright, R. D.; Dumesic, J. A. Catal. Lett. 1998, 51, 139

(32) Ramaker, D. E.; Mojet, B. L.; Garriga-Oostenbrink, M. T.; Miller, J. T.; Koningsberger, D. C. Phys. Chem. Chem. Phys., submitted. 